\title{
Albert Kaganovich
}

\section{The Mashhadi Jews (Djedids) in Central Asia}


